\title{
Telemedicine: An Educational and Healthcare Tool
}

\author{
F.F. Fenech \\ Faculty of Medicine and Surgery, University of Malta, Msida, Malta
}

Telemedicine literally means 'medicine at a distance'. It is about bringing specialist knowledge to the patient and doctor from afar by use of communications technology. Using telecommunication networks to communicate information, it provides health care consultation and education. Physicians, hospitals and medical schools have been exploring the uses of telemedicine since 1964, however, it was only in the late 1980s and the 1990s that its practical applications were recognised and started being evaluated. There is increasing interest in the use of telemedicine as a means of health care delivery and to its increasing relevance as an educational tool at both the undergraduate and postgraduate level. This is partly because technological advances have made the equipment less expensive and simple to use.

Indeed, in the United States of America, telehealth is a major growth area. A 1997 survey reported 139 active programmes, conducting over 40,000 non-teleradiology consultations in 35 specialties, primarily mental health, cardiology, ophthalmology, orthopaedics and dermatology. About $75 \%$ of these utilised video conferencing; the others used store-and-forward formats. About 20\% of consultations were carried out in prisons. In the same year, there were about 250,000 diagnostic teleradiology readings, with teleradiology becoming a significant commercial activity. In August 1996, Norway became the first country to implement an official telehealth fee schedule, making all telehealth services reimbursable by the national health insurer.

\section{KARGER}

Fax +41613061234

E-Mail karger@karger.ch

www.karger.com

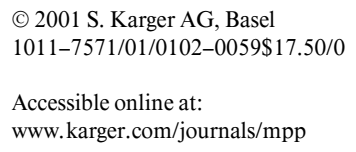

Although telephone consultation falls within the broad definition of telemedicine, the term is usually taken to refer to more sophisticated applications such as video conferencing and the transmission of medical images. Modern digital cameras can reproduce diagnostic quality images of clinical features, of ECGs, and of microscopic films; they can also reproduce high quality images of most radiographs. This system has been successfully used by British Forces in the war zones of Bosnia and Kosovo and is now being emulated in civilian practice in the UK, USA and in previously isolated hospitals in the Third World. Indeed, the US armed forces in Kuwait carried out a study to determine the relative ease with which an offthe-shelf ophthalmic telemedicine package could be successfully applied from within a remote theatre of operations and found that it could be successfully used from a remote deployed site. Indeed, telemedicine has proved itself both from the technical and clinical aspects.

Telemedicine has been used for undergraduate, graduate and continuing medical education (CME). Video conferencing has been used for meetings, tutorials, presentations and training events. It has made it possible for medical, pharmacy and nursing students to receive part of their education at distant sites. INSURRECT is a programme which provides interactive on-line teaching in surgical procedures for medical undergraduates in hospitals in Cambridge, London, Newcastle, Manchester, Bristol and Edinburgh. Indeed, this educational tool is also being applied in other specialities. 
It is, however, in the area of CME that telemedicine has made its major impact. Transmission of formal CME activity breaks down distant barriers in medical education, keeping individuals connected to their colleagues, peers and consultants in a process of continuous medical education. Telemedicine makes the participation of doctors in CME activity easier because it provides materials, which can be used by the physician at a convenient time and location. Video conferencing of Grand Rounds in various specialities as well as communication between multiple sites during an interactive video conferencing is being increasingly practiced. These activities enable doctors to receive the necessary CME credits. Self-teaching modules involving the use of computers and interactive video discs are increasingly available at both undergraduate and postgraduate levels.

Telemedicine does, however, raise confidentiality and security concerns even though studies of interactive consulting have been performed in a diversity of settings and most suggest that patients are satisfied with the mode of health care delivery. Despite this, one must not forget the basic right of patients to privacy of their medical information and records. All the means of communication in telemedicine, be it closed telecommunications network, the internet and cellular equipment, are vulnerable to security breaches of confidentiality which must be preserved, and some form of encryption must be utilised.

The rapid progress in telecommunications is changing many aspects of medical practices in education. Indeed, some medical schools, e.g., the Medical Faculty of Sao Paolo in Brazil, has established the discipline of telemedicine. The power of the computer and the universality of the internet connections will make telemedicine on a global scale a reality. The need to train the new generation of medical students and doctors in telemedicine is being increasingly recognised. However, one should guard against those situations where the doctor/patient relationship during any form of such activity, be it undergraduate, postgraduate or as part of the delivery of health care, is threatened. Though the era of modern medicine is full of promise and excitement, it is vital that the invasion of the patient's privacy is not allowed to take place under the guise of progress. This danger to privacy does exist and we must therefore tackle the ethical and social issues that accompany medical progress. We must never lose sight of the fact that we should be the guardians of our patients' best interest.

Due to the importance of telematics as an educational and healthcare tool, Medical Principles and Practice will run a series of review articles on the use of telematics in education and health care delivery. In this issue, Dr. J.R. Maclean, Medical College of Georgia, USA, K.L., White, Institute for Health Services Research, Georgia, USA, and J.Etchason, Center for Healthcare Improvement, BlueCross and BlueShield of Georgia, Atlanta, Ga., USA, discuss distance learning in undergraduate education: methods, opportunities and challenges for institutions and educators. In the next issue, Dr. J.N. Norman, University of Aberdeen, UK, will discuss telematics in postgraduate education. In the final issue of the year, Drs. M. Loane and R. Wootton, Centre for Online Health, University of Queensland, Australia, will review telehealth. 